нии // Инновационное движение в российском школьном образовании. М.: Изд-во «Парсифаль», 1997. С. 336-353.

14. Кларин М.В. Педагогическая технология в учебном процессе. Анализ зарубежного опыта. М.: Знание, 1989. 180 с.

15. Философия: Энциклопедический словарь / под ред. А.А. Ивина. М.: Гардарики, 2004. 1072 с.

16. Каминская М.В., Эльконина Д.Б., Давыдова В.В. Концепция профессионального развития учителя в системе развивающего образования // Психологическая наука и образование. 2004. № 3. С. 34-43.

17. Фрумин И.Д. Введение в теорию и практику демократического образования. Красноярск: Знание, 1998. С. $40-42$.

18. Адольф В.А., Ильина Н.Ф. Подготовка педагога к инновационной деятельности в процессе профессионального становления. М.: Альма-Матер, 2006. № 10. C. 18-20.

19. Дири М.И. Значимость инновационных преобразований при подготовке современных специалистов // Современные технологии подготовки кадров и повышения квалификации специалистов нефтегазового производства: тез. IV научно-практической конференции с междунар. участием. Самара, 2017. C. 23.

20. Адольф В.А. Профессиональная компетентность современного учителя: монография. Красноярск, 1998. 310 с.

21. Адольф В.А., Ильина Н.Ф. Инновационная деятельность педагога в процессе его профессионального становления. Красноярск: Поликом, 2007. $190 \mathrm{c}$.

22. Рябинова Е.Н., Марченкова Л.А. К вопросу об актуальности формирования вербальных компетенций студентов технических вузов // Вестник Самарского государственного технического университета. Серия «Психолого-педагогические науки». 2015. № 2 (26). С. 163-170.

23. Рябинова Е.Н., Марченкова Л.А. Формирование вербальных компетенций в процессе профессиональной подготовки будущих инженеров // Вектор науки ТГУ. Серия: педагогика, психология. 2015. № 4(23). С. 158-163.

\title{
EDUCATOR'S INNOVATIVE ACTIVITY IN THE COURSE OF PROFESSIONAL TRAINING
}

(C) 2017

Diri Marta Igorevna, postgraduate student of Psychology and Pedagogy Department Samara State Technical University (Samara, Russian Federation)

Abstract. The paper deals with modern education as a major factor of new quality formation of economy and society. The author analyses problems of education content change, problems of innovative technologies introduction in teaching and educational process. A teacher's innovative activity as manifestation of his/her professional creativity is also studied. It is noted that professional training of a teacher is a continuous life-long process which defines a possibility of a person's boundless development. It is shown that the process of professional training has some features, occurs in joint activity and communication. Theoretical and experimental researches in the field of a teacher's innovative activity are analyzed, innovative development of the educational process is considered. The author emphasizes that today the majority of professional pedagogical public consists of teachers whose professional training began during industrial development of society, as well as teachers-trainees who quite recently passed a stage of vocational training. For this reason, possibilities of ensuring readiness of pedagogical personnel for innovative activity are considered at different stages of professional training. The author shows that understanding of theoretical knowledge and then obtaining practical experience allows to develop professional and pedagogical style of thinking, provide innovative updating of a teacher's professional activity.

Keywords: professional training; educator; innovative activity; innovative technologies; creative process; innovations; professional activity; pedagogical formation; potential; professional competences; professionalism; professional development; qualifications; personality.

УДК 378.09

\section{ФОРМИРОВАНИЕ ОРГАНИЗАТОРСКИХ СПОСОБНОСТЕЙ В СФЕРЕ ПРЕДПРИНИМАТЕЛЬСКОЙ ДЕЯТЕЛЬНОСТИ У БУДУЩИХ СОТРУДНИКОВ ПЕНИТЕНЦИАРНОЙ СИСТЕМЫ}

(C) 2017

Ежова Олеся Николаевна, кандидат психологических наук, профессор кафедры управления и информационно-технического обеспечения деятельности УИС

Улендеева Наталия Ивановна, кандидат педагогических наук, доцент кафедры управления и информационно-технического обеспечения деятельности УИС Самарский юридический институт ФСИН России (2. Самара, Российская Федеращия)

Аннотациия. В статье анализируются условия и требования, предъявляемые к организации производственной деятельности в учреждениях пенитенциарной системы на современном этапе развития социальноэкономических отношений, предполагающие необходимость формирования у сотрудников организаторских способностей в предпринимательской деятельности. Рассмотрены подходы к определению организаторских 
способностей в предпринимательской деятельности и дано авторское определение данного понятия через индивидуально-психологические особенности личности, необходимые для успешного осуществления организации производственной деятельности, предполагающей эффективное использование ресурсов и факторов производства для достижения экономических целей. Для эффективного формирования профессиональных компетенций в сфере производственной деятельности предлагается выделить состав и структуру организаторских способностей курсантов и слушателей ведомственных вузов, включающие когнитивный, эмоционально-волевой и поведенческий компоненты; целенаправленно организовать учебный процесс по дисциплинам «Экономика» и «Основы управления в правоохранительных органах», способствующий изучению сущности и структуры производственных отношений в уголовно-исполнительной системе, выявлению механизмов, условий и факторов по управлению профессиональными ресурсами осужденных. На факультативных занятиях предлагается внедрять технологию формирования организаторских способностей в предпринимательской деятельности через практико-ориентированную модель обучения, предполагающую межкафедральный характер обучения, при котором образовательный процесс носит непрерывный формирующий характер; на учебных занятиях использовать интегрированные задания, направленные на формирование у курсантов когнитивного компонента организаторских способностей в предпринимательской деятельности.

Ключевые слова: организаторские способности; предпринимательская деятельность; пенитенциарная система; когнитивный компонент; поведенческий компонент; эмоционально-волевой компонент; волевые качества и способности личности; учебный процесс; учебные дисциплины; практико-ориентированная модель обучения.

Социально-экономические процессы в России, характеризующиеся поступательным развитием частного сектора в экономике регионов, оказывают непосредственное влияние на экономическую среду, в которой функционируют производственные структуры учреждений уголовно-исполнительной системы (УИС).

В настоящее время все закупки, которые производят учреждения УИС, осуществляются в соответствии с Федеральным законом от 05.04.2013 № 44Ф3 «О контрактной системе в сфере закупок товаров, работ, услуг для обеспечения государственных и муниципальных нужд», вступившим в силу с 1 января 2014 года. Закон позволяет реализовать системный подход к формированию, размещению и исполнению государственных контрактов, обеспечить прозрачность всего цикла закупок от планирования до приемки и анализа контрактных результатов, предотвратить коррупцию и другие злоупотребления в сфере обеспечения государственных нужд [1]. Осуществление эффективных закупок товаров, работ и услуг для государственных нужд, в соответствии с этим законом, требует от будущих сотрудников пенитенциарной системы необходимых знаний в области рыночных отношений и умений реализовать эти знания на практике.

В связи с этим требованием возникает острая необходимость в специалистах, выполняющих функции по организации производства в УИС, которые способны к экономической и социально-экономической деятельности в области организации производства, при трудоустройстве осужденных в центры трудовой адаптации осужденных (ЦТАО), лечебнопроизводственные мастерские (ЛПМ) и учебнопроизводственные мастерские (УПМ) исправительных учреждений (ИУ), к деятельности в производственно-экономических и информационно-аналитических службах учреждений УИС.

Поэтому, в условиях современной компетентностно-ориентированной парадигмы высшего образования, предъявляются новые требования к профессиональным компетенциям и к качеству подготовки курсантов и слушателей вузов Федеральной службы исполнения наказаний, в том числе к подготовке специалистов профиля «Правоохранительная дея- тельность», специализации «Организация режима и надзора в ИУ УИС - организация режима и надзора при функционировании производственных объектов».

Возрастает заинтересованность Федеральной службы исполнения наказаний (ФСИН) в сотрудниках, владеющих не только многофункциональной компетентностью по организации режима, надзора, охраны в исправительных учреждениях, но и инновационным, творческим мышлением, готовых к поиску и реализации путей экономического роста производственных комплексов УИС.

В свете формирования нового вида взаимодействия по реализации продукции ФСИН и коммерческих структур - создания торгового дома ФСИН приоритетной становится задача подготовки курсантов и слушателей ведомственных вузов к производственно-предпринимательской деятельности, формирование у них организаторских способностей в сфере предпринимательства и навыков предпринимательской культуры.

Однако традиционное профессиональное образование только в двух вузах ФСИН формирует специальные знания и профессиональные компетенции в области организации производства при трудоустройстве осужденных в ЦТАО, ЛПМ или УПМ учреждений УИС, что полностью не решает проблемы обеспечения производственных структур УИС квалифицированными специалистами, способными организовать труд осужденных на рабочих местах, участках, в производственных цехах учреждений УИС.

Разработка модели организации «индивидуальной трудовой деятельности осужденных», о которой говорится в новой редакции Концепции развития уголовно-исполнительной системы Российской Федерации до 2020 года [2], потребует от образовательных организаций разработки новой системы подготовки специалистов, способных к реализации управленческой функции в экономической деятельности, которая позволяла бы сотрудникам УИС участвовать в процессе сопровождения индивидуальной трудовой деятельности спецконтингента. Данный вид деятельности сотрудников УИС предусматривает обязательное овладение предпринимательскими умениями, навыками и компетенциями по организации ма- 
лых производств на территории ИУ такими, как: закупка оборудования, сырья и материалов, продвижение произведенных товаров на рынке, реклама продукции, поддержка инициативы осужденных заниматься индивидуальной производственной деятельностью и т.п.

Поэтому необходимо развитие организаторских способностей в сфере предпринимательской сфере у курсантов и слушателей вузов ФСИН при обучении по специальностям «Правоохранительная деятельность» и «Юриспруденция», формирования у них профессиональной интуиции, осознанной предпринимательской инициативы, направленной на реализацию эффективной производственной деятельности каждого осужденного.

Традиционно под организаторскими способностями понимают индивидуально-психологические особенности личности, необходимые для успешного осуществления организаторской деятельности. Однако организация внебюджетной (предпринимательской) деятельности в исправительных колониях имеет свои особенности и специфику $[3 ; 4 ; 5]$, основными из которых, по нашему мнению, являются следующие. В первую очередь, данный вид деятельности необходимо организовывать для реализации исправительной функции по ресоциализации осужденных. Необходимо также соблюдать все режимные требования на производственных участках исправительных колоний. Третья особенность заключается в том, что осужденные не имеет соответствующей специальности и квалификации, поэтому необходимо их постоянное специальное обучение и переобучение. Кроме этого, для увеличения количества работников из числа осужденных, занятых на производстве, необходимо разработать систему их мотивации, которая позволяла бы эффективно регулировать процесс заинтересованности в результатах труда.

Для организации эффективного производства в условиях ИУ необходим также строгий финансовоаналитический учет всех статей расходов. Сотрудники колоний, отвечающие за работу производственных участков, должны уметь прогнозировать и планировать свою деятельность.

В структуре организаторских способностей будущих сотрудников пенитенциарной системы в сфере предпринимательской деятельности можно выделить когнитивный, эмоционально-волевой и поведенческий компоненты [6]. Специфика организации внебюджетной (предпринимательской) деятельности в исправительных колониях во многом определяет их содержание.

Когнитивный компонент, помимо знаний о целях, задачах организаторской деятельности и требованиях, предъявляемых к процессу и ее результатам, должен включать знания о производственном процессе, особенностях рынка и нормативно-правовых актах, регламентирующих закупку товаров, выполнение работ и услуг для государственных нужд.

Содержание поведенческого компонента организаторских способностей сотрудника УИС составляют его умения и навыки применять различные методы управленческой деятельности, используя формы ее осуществления с учетом соответствующих специфических ситуаций.

Учитывая тот факт, что производство в УИС непосредственно связано с организацией труда осуж- денных и предназначено для обеспечения для них возможности трудовой занятости, особое значение приобретает эмоционально-волевой компонент организаторских способностей сотрудников пенитенциарной системы. Значимость данного компонента обусловлена тем фактором, что, несмотря на то, что именно трудовая деятельность может обеспечить осужденным последующую успешную ресоциализацию, их мотивация к труду зачастую остается очень низкой. Основным фактором, который не способствует ее повышению, является криминогенная субкультура и влияние на осужденного криминогенно зараженной среды. Поэтому эмоционально-волевой компонент предполагает наличие у сотрудников УИС таких личностных качеств и способностей, как: самообладание и выдержка, самостоятельность, оперативность в принятии решений, принципиальность и умение принимать решение в экстремальных условиях [7], а также способностей преодолевать трудности, противостоять соблазнам и чужому влиянию.

Для полноты исследования проблемы, вынесенной в заголовок нашей статьи, рассмотрим содержание понятия «предпринимательские способности». В экономическом словаре данный термин определяется так: «набор качеств, умений, способностей человека, позволяющих ему находить и использовать лучшее сочетание ресурсов для производства, продажи товаров, принимать разумные последовательные решения, создавать и применять новшества, идти на допустимый, оправданный риск» [8]. В словаре по экономической теории под предпринимательскими способностями понимается «особый вид человеческого pecурса, заключающийся в способности наиболее эффективно (с положительной результативностью) использовать все другие факторы производства» [9].

Таким образом, организаторские способности в предпринимательской деятельности можно трактовать как индивидуально-психологические особенности личности, необходимые для успешного осуществления организации производственной деятельности, предполагающей эффективное использование ресурсов и факторов производства для достижения экономических целей.

Все вышеизложенное позволило нам сформулировать проблему подготовки специалистов, занятых на производственных участках в ИУ, следующим образом: какой должна быть технология эффективного формирования организаторских способностей в сфере предпринимательства у будущего сотрудника УИС, готового к реализации Концепции развития УИС в части разработки модели индивидуальной трудовой занятости осужденных?

С учетом этого, для формирования у будущих сотрудников УИС организаторских способностей в предпринимательской деятельности предлагаются следующие формальные и содержательные изменения и дополнения организации учебного процесса в высших ведомственных учебных заведениях ФСИН России:

1) в процессе изучения дисциплин «Экономика» и «Основы управления в УИС» необходимо целенаправленно обучать курсантов сущности и структуре производственных отношений в УИС, выявлять механизмы, условия и факторы, способствующие управлению профессиональными ресурсами осужденных; 
2) на факультативных занятиях внедрять технологию формирования организаторских способностей в предпринимательской деятельности через практикоориентированную модель обучения, предполагающую межкафедральную реализацию, при которой образовательный процесс будет носить непрерывный формирующий характер;

3) использовать в учебном процессе интегрированные задания, специальные курсы дисциплин, направленные на формирование у курсантов когнитивного компонента организаторских способностей в предпринимательской деятельности;

4) внедрить в процесс подготовки будущих сотрудников пенитенциарной системы показатели и диагностический инструментарий мониторинга уровня сформированности у курсантов поведенческого и эмоционально-волевого компонентов организаторских способностей в предпринимательской деятельности.

Таким образом, можно сделать вывод о том, что для успешного развития внебюджетной (предпринимательской) деятельности в учреждениях УИС в учебные планы вузов ФСИН России необходимо ввести дисциплину «Управление производственными структурами в УИС» или соответствующие факультативы и спецкурсы, например: «Организация и управление внебюджетной (предпринимательской) деятельности на базе социальных центров трудовой адаптации», «Экономика и управление профессиональными ресурсами УИС», «Управление развитием производственных структур УИС», направленные на формирование у курсантов необходимых компонентов организаторских способностей в предпринимательской деятельности. Обучение курсантов на таких факультативах и спецкурсах будет способствовать эффективному выполнению ими управленческих функций в своей служебной профессиональной деятельности в центрах трудовой адаптации осужденных и обеспечивать развитие производственных структур УИС.

\section{СПИСОК ЛИТЕРАТУРЫ:}

1. Федеральный закон от 05.04.2013 № 44 Ф3 (ред. от 28.03.2017) «О контрактной системе в сфере закупок товаров, работ, услуг для обеспечения государственных и муниципальных нужд» [Электронный ресурс] // СПС «Консультант Плюс».

2. Распоряжение Правительства Российской Федерации от 14 октября 2010 г. № 1772-р (ред. 23.09.2015) «Об утверждении Концепции развития уголовно-исполнительной системы Российской Федерации до 2020 года» [Электронный ресурс] // СПС «Консультант Плюс».

3. Мелкумян Г.И., Улендеева Н.И. Формирование новых организационно-финансовых взглядов на производственную деятельность УИС // Вестник Самарского юридического института. 2015. № 2 (16) C. $100-104$.

4. Грязнов С.А. Особенности формирования занятости в сфере малого бизнеса в условиях пенитенциарных учреждений // Молодежь и экономика: новые взгляды и решения. Волгоград: Волгоградский государственный технический университет, 2015. С. 8889.

5. Грязнов С.А., Улендеева Н.И. Особенности механизма управления предпринимательской деятельностью в учреждениях пенитенциарной системы в условиях развития рыночных отношений // Вестник Владимирского юридического института. 2015. № 1 (34). C. $20-25$.

6. Иванова С.В. Психолого-педагогические условия формирования организаторских способностей будущих учителей начальных классов в педагогическом колледже: автореф. дис. ... канд. психол. наук. Самара, 2013. 26 c.

7. Ежова О.Н., Иванова С.В. Формирование организаторских способностей сотрудников уголовноисполнительной системы как условие эффективности их профессиональной деятельности // Евразийский юридический журнал. 2014. № 12. С. 202-207.

8. Райзберг Б.А., Лозовский Л.Ш., Стародубцева Е.Б. Современный экономический словарь. 2-е изд., испр. М.: ИНФРА-М, 1999. 479 с.

9. Теплов В.П. Словарь по экономической теории. Новосибирск: РГТЭУ, Новосибирский филиал, 2007. $136 \mathrm{c}$.

\section{ORGANIZATIONAL SKILLS DEVELOPMENT IN THE SPHERE OF ENTREPRENEURIAL ACTIVITY OF PENITENTIARY SYSTEM PROSPECTIVE EMPLOYEES}

(C) 2017

Yezhova Olesya Nikolaevna, candidate of psychological sciences, professor of Penitentiary Service Management and Information Technology Department

Ulendeeva Natalia Ivanovna, candidate of pedagogical sciences, associate professor of Penitentiary Service Management and Information Technology Department Samara Law Institute of the Federal Penitentiary Service of Russia (Samara, Russian Federation)

Abstract. The paper analyzes conditions and requirements for production activities organization at penitentiary system institutions at the present stage of social and economic relations development that imply the necessity for entrepreneurial activities organizational skills. The authors consider approaches to the definition of entrepreneurial activity organizational abilities and their own definition of this concept is given through the individual psychological characteristics of the individual that is necessary for successful productive activities organization that involves effective production resources and factors use to achieve economic goals. For effective professional competencies development in the field of production the authors propose to identify the composition and structure of cadets and students' organizational abilities, including cognitive, emotional-volitional and behavioral components. They suggest organizing educational process of «Economics» and «Fundamentals of Management in Law Enforcement» students that could study nature and structure of production relations in the penal correction system, identify mechanisms, conditions and factors for convicts' professional resources management. In elective classes the authors propose to in- 
troduce technology of organizational skills development in entrepreneurial activity through a practice-oriented model of training, which assumes the inter-faculty nature of education where the educational process has a continuous formative character. At the training sessions the authors propose to use integrated tasks that develop cognitive component of organizational abilities in business activity among cadets.

Keywords: organizational skills; business activity; penitentiary system; cognitive component; behavioral component; emotional-volitional component; volitional qualities and abilities of the individual; educational process; educational disciplines; practical-oriented model of training.

УДК 378

\section{РАЗВИТИЕ ПРОФЕССИОНАЛЬНОГО САМООПРЕДЕЛЕНИЯ СТУДЕНТА НА ОСНОВЕ СМЫСЛООБРАЗОВАТЕЛЬНОЙ ДЕЯТЕЛЬНОСТИ}

(C) 2017

Карпова Ольга Леонидовна, доктор педагогических наук, профессор кафедры гуманитарных, естественнонаучных и математических дисциплин Уральский сочиально-экономический институт (филиал) Академии труда и социальньх отношений (2. Челябинск, Российская Федераџия)

Найн Альберт Яковлевич, доктор педагогических наук, профессор, заведующий кафедрой педагогики Уральский государственньй университет физической культуры (г. Челябинск, Российская Федерация)

Аннотация. В статье на основе изучения социального заказа общества, нормативной базы, а также собственного опыта преподавательской деятельности определена актуальность и выявлены ключевые проблемы, затрудняющие в современном обществе процесс развития профессионального самоопределения обучающихся. Обозначены ключевые противоречия, обусловившие возникновение научной проблемы развития профессионального самоопределения студентов на основе смыслообразовательной деятельности. Представлена достаточно обширная теоретическая база, служащая базисом для раскрытия сущности смыслообразовательной деятельности обучающихся как психолого-педагогической проблемы. Изучены современные исследования, связанные с развитием смыслообразующего образования студентов. Разработана и показана структура смыслообразовательной деятельности обучающихся, включающая следующие содержательные компоненты: компонент самосознания, когнитивный, мотивационно-смысловой и ценностно-регулятивный. В совокупности компоненты разработанной структуры смыслообразовательной деятельности студента выполняют функции детерминации и регуляции профессиональной деятельности, конструирования, саморазвития и самоконтроля личности, выступая основой развития профессионального самоопределения обучающихся. Предложены критерии оценки структуры смыслообразовательной деятельности: увлеченность профессиональной деятельностью; широта интересов; профессиональное самосознание; осознанное и самостоятельное обретение смыслов профессиональной деятельности в системе жизненных целей, планов и программ. Сформулированы педагогические условия, способствующие эффективному развитию профессионального самоопределения студентов вуза на основе смыслообразовательной деятельности.

Ключевые слова: развитие; профессиональное самоопределение; студенты; смыслы; основа; смыслообразовательная деятельность; структура; содержательные компоненты; критерии; педагогические условия; компонент самосознания; когнитивный компонент; мотивационно-смысловой компонент; ценностно-регулятивный компонент.

Проблема развития профессионального самоопределения обучающихся является предметом многих научных изысканий. Вместе с тем, как показывают наши исследования $[1 ; 2]$, она не в полной мере осознана как нормированный процесс организации творческого продуктивного взаимодействия обучающегося с целью развития его потребностей и способностей [3, с. 193-194]. Эти смыслосодержательные характеристики относятся к тем мировоззренческим вопросам, ответы на которые до сих пор не обоснованы в полной мере. Поэтому на каждом новом этапе развития общества и государства эти вопросы требуют поиска неординарных решений.

Ключевые посылы для формулировки такого рода решений определены, прежде всего, социальным заказом общества и зафиксированы на законодательном уровне. Так, в государственной программе РФ «Развитие образования» на 2013-2020 годы отмечается широкий позитивный потенциал молодежи: мобильность, инициативность, восприимчивость к инновационным изменениям, новым технологиям, спо- собность противодействовать современным вызовам. Вместе с тем, определены и ключевые проблемы, затрудняющие процесс развития профессионального самоопределения обучающихся [4]:

- около одной трети молодых людей в современной России не в состоянии успешно адаптироваться к современной экономической ситуации и реализовать свои профессиональные устремления;

- происходит деформация духовно-нравственных ценностей, размываются моральные ограничители на пути к достижению личного успеха;

- у значительной части молодежи отсутствуют стремление к общественной деятельности, навыки самоуправления;

- вызывает опасение тенденция «потери человеческого капитала», так как молодые люди не полностью используют имеющийся у них потенциал, что в итоге может привести к замедлению социальноэкономического развития нашей страны и др.

В этой связи ключевыми задачами в сфере высшего образования, как отмечается в данном доку- 